\title{
One is the new six: The International Society of Urological Pathology (ISUP) patient-focused approach to Gleason grading
}

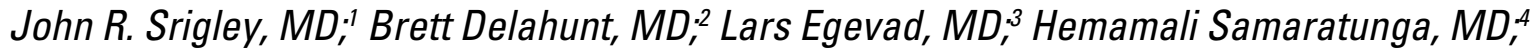 \\ John Yaxley, MD; ${ }^{5}$ Andrew J. Evans, $M D^{6}$
}

Trillium Health Partners and University of Toronto, Mississauga, ON, Canada; ' 2 Department of Pathology and Molecular Medicine, Wellington School of Medicine and Health Sciences, University of Otago, Wellington, New Zealand; ${ }^{3}$ Department of Oncology and Pathology, Karolinska Institutet, Stockholm, Sweden; ${ }^{4}$ Aquesta Uropathology and University of Queensland, Brisbane, Queensland, Australia; ${ }^{5}$ Department of Urology, Royal Brisbane Hospital and University of Queensland, Brisbane, Queensland, Australia; 6 University Health Network and University of Toronto, Toronto, ON, Canada

Cite as: Can Urol Assoc J 2016;10(9-10):339-41. http://dx.doi.org/10.5489/cuaj.4146

$\mathrm{F}$ ifty years ago, Donald Gleason published his eponymous grading system and demonstrated its prognostic utility in clinical trials designed to investigate hormonal therapies for prostate cancer. ${ }^{1}$ Over the ensuing decades, the Gleason system has been widely used in clinical practice and research, and has been endorsed as the global grading standard for prostate cancer by numerous organizations, including the World Health Organization (WHO) and the Union for International Cancer Control (UICC). ${ }^{2,3}$

The diagnosis and treatment of prostate cancer has changed dramatically in recent decades and as the new millennium dawned, a modernization of the Gleason system commenced. In 2005, the International Society of Urological Pathology (ISUP) convened a consensus conference at which the patterns comprising the various Gleason grades were clarified, along with the practical rules for their application. ${ }^{4}$ There was emphasis on how the grading system should be employed in biopsy practice. It was agreed that Gleason grades 1 and 2 should not be used in biopsy reporting. The consensus was that these uncommon patterns should be restricted to occasional tumours, usually originating in the transition zone, that were only diagnosable in transurethral resections or radical prostatectomy specimens. As a consequence of this, the Gleason scale for biopsies started at Gleason score six. Cribriform patterns, with the exception of the uncommon small, round, and regular cribriform structures, and so-called poorly formed glands (without wellformed lumens) were included as features of Gleason pattern (grade) 4. Additionally, it was decided that in biopsies where three Gleason patterns are present, the dominant pattern and worst remaining one, irrespective of its extent should comprise the Gleason score.

Over the following decade, the changes endorsed by ISUP in 2005 resulted in an upgrading of prostate cancer, with a greater proportion of patients being classified within high-risk categories. ${ }^{5-7}$ Additionally, the recalibration of the Gleason scale resulted in practical problems for both urologists and oncologists, who had to explain to patients that Gleason 6 cancer was a low-grade tumour and that active surveillance, in many cases, was the treatment of choice. With the availability of information from the web and other sources, patients were often left confused by the concept of Gleason 6 being considered the most favourable grade on biopsy, when the Gleason system spanned scores 2-10. They were asking, "Wouldn't my Gleason 6 cancer be considered intermediate grade?" Even for stratification of patients into a high-profile clinical trial, Gleason 6 was considered intermediate-grade rather than low-grade. ${ }^{8}$ Additionally, there was a suggestion by some clinicians, epidemiologists, and public health physicians to re-name Gleason 6 adenocarcinoma as "indolent lesion of epithelial origin (IDLE)." ${ }^{\prime 9}$

Because of these and other unresolved issues from the 2005 consensus conference, the ISUP convened a second meeting in 2014 to further clarify details of prostate cancer grading based on evidence generated since 2005 wherever possible. This conference was attended by 65 pathologists and 17 clinicians from 19 countries. ${ }^{10}$ At the meeting it was agreed that all cribriform and glomeruloid patterns should be classified as Gleason grade 4. It was further agreed that grading for mucinous tumours should be based upon the underlying architectural pattern and not be influenced by the mucin component. Finally, intraductal carcinoma of prostate, which has come to prominence as an important adverse prognostic factor in the last decade, would not be graded and only the associated invasive component would be assigned a Gleason score.

A major focus of the 2014 meeting was the refinement and endorsement of a prognostic grouping system initially proposed by Eifler et al in 2012. ${ }^{11}$ Over the years, numerous grade grouping systems have been proposed and the current system is a natural progression of this (Table 1). ${ }^{12-25}$ The ISUP grades, which are based on the grouping of Gleason scores and patterns, are shown in Table 2. Arguably, the 


\begin{tabular}{|c|c|c|}
\hline Year & Gleason groupings & Reference \\
\hline 1977 & 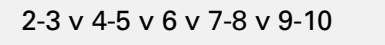 & Gleason ${ }^{12}$ \\
\hline 1987 & $2-5 \vee 6-7 \vee 8-10$ & Pilepich ${ }^{13}$ \\
\hline 1990 & $2-5 \vee 6 \vee 7 \vee 8-10$ & Bagshaw $^{14}$ \\
\hline 1991 & $2-4$ v 5-7 v 8-10 & Russell 15 \\
\hline 1993 & $2-6 \vee 7-10$ & Epstein $^{16}$ \\
\hline 1994 & $2-4 \vee 5-6 \vee 7 \vee 8-10$ & Ohori $^{17}$ \\
\hline 1995 & $2-3 \vee 4-6 \vee 7 \vee 8-10$ & Zagars $^{18}$ \\
\hline 1997 & $2-4 \vee 5 \vee 6 \vee 7 \vee 8-10$ & Partin $^{19}$ \\
\hline 1998 & $2-6 \vee 7 \vee 8-10$ & $\mathrm{D}^{\prime} \mathrm{Amico}^{20}$ \\
\hline 2000 & $2-4 \vee 5-6 \vee 7-10$ & Freedland $^{21}$ \\
\hline 2006 & $<6 \vee 3+4 \vee 4+3 \vee 8-10$ & Donohue $^{22}$ \\
\hline 2007 & $2-6 \vee 3+4 \vee 4+3 \vee 8-10$ & Makarov $^{23}$ \\
\hline 2011 & $\leq 3+4 \vee 4+3 \vee 8 \vee 9-10$ & Tolonen ${ }^{24}$ \\
\hline 2012 & $2-6 \vee 3+4 \vee 4+3 \vee 8 \vee 9-10^{* *}$ & Eifler $^{11}$ \\
\hline
\end{tabular}

most significant element of the new system is the grouping of all cases with Gleason scores $\leq 6$ as grade 1 . The identification of this very low-risk category helps alleviate patients' concerns regarding the intermediate placement of Gleason score 6 tumours on the 2-10 Gleason scale. Many patients with these low-grade tumours can be followed by active surveillance and the reclassification of these as ISUP grade 1 emphasizes their indolent nature.

ISUP grades 2 and 3 stratify Gleason 7 into two categories based on whether well-formed glands or poorly formed/ fused/cribriform glands predominate. These two categories have long been known to have different prognostic significance and in fact, Gleason scores $7(3+4)$ and $7(4+3)$ have been incorporated into nomograms and risk calculators for many years. ${ }^{26-28}$ Subsequent to the 2014 consensus meeting, it was decided by the ISUP working group that the percentage pattern 4 should be documented in all Gleason 7 tumours, with agreement for this decision being obtained from participants by web-polling. The documentation of percentage pattern 4 is particularly important in ISUP grade 2 cancers, as the active surveillance guideline published by Cancer Care Ontario and subsequently endorsed by the American Society of Clinical Oncology, indicates that selected patients with Gleason 7 tumours who have $\leq 10 \%$ pattern 4 tumour, can be considered for active surveillance protocols. ${ }^{29,30}$ The documentation of percent pattern 4 in Gleason 7 cancers is also recently recommended by the $\mathrm{WHO}^{31}$

The grade 4 category of the ISUP grading system is heterogeneous and consists predominantly of tumours with Gleason score $4+4=8$, with less common Gleason patterns $3+5$ and $5+3$ also being included. These tumours behave in a significantly more aggressive manner than ISUP

\begin{tabular}{|c|c|c|}
\hline $\begin{array}{l}\text { ISUP } \\
\text { grade }\end{array}$ & $\begin{array}{c}\text { Gleason } \\
\text { scores }\end{array}$ & Definition \\
\hline Grade 1 & $2-6$ & Only individual discrete well-formed glands \\
\hline Grade 2 & $3+4=7$ & $\begin{array}{l}\text { Predominantly well-formed glands with } \\
\text { lesser component of poorly formed/fused/ } \\
\text { cribriform glands }\end{array}$ \\
\hline Grade 3 & $4+3=7$ & $\begin{array}{l}\text { Predominantly poorly formed/fused/ } \\
\text { cribriform glands with lesser component of } \\
\text { well-formed glands }\end{array}$ \\
\hline \multirow[t]{3}{*}{ Grade 4} & $4+4=8$ & Only poorly formed/fused/cribriform glands \\
\hline & $3+5=8$ & $\begin{array}{l}\text { Predominantly well-formed glands and } \\
\text { lesser component lacking glands (or with } \\
\text { necrosis) }\end{array}$ \\
\hline & $5+3=8$ & $\begin{array}{l}\text { Predominantly lacking glands (or with } \\
\text { necrosis) and lesser component of } \\
\text { well-formed glands }\end{array}$ \\
\hline Grade 5 & $9-10$ & $\begin{array}{l}\text { Lacking gland formation (or with necrosis) } \\
\text { with or without poorly formed/fused/ } \\
\text { cribriform glands }\end{array}$ \\
\hline
\end{tabular}

grade $3 .^{32-34}$ Grade 5 is the highest ISUP grade and consists of Gleason scores 9 and 10. These latter tumours are associated with poor prognosis. ${ }^{32-34}$ From a practical perspective, it is recommended that the ISUP grade be reported in all needle biopsies, along with the corresponding Gleason patterns and scores. ${ }^{10}$

While ISUP grading represents a significant advance in prostate pathology, future modifications will likely be required. In particular, ISUP grade 4 tumours consisting of Gleason patterns $5+3$ have been shown to have the worst prognosis compared to those with only pattern 4 or $3+$ 5 and may be more appropriately included in ISUP grade $5 .{ }^{35}$ Other problem areas include the level (individual core, specimen, case) at which ISUP grading should apply, the handling of grade diversity across specimens, and whether ISUP grade should be based on the worst or composite Gleason score. A further major unresolved issue is the lack of consensus as to how tertiary patterns should be handled in radical prostatectomy specimens.

Despite these issues, the ISUP grading system addresses several of the criticisms faced by urological pathologists related to the inaccuracy of Gleason scale and perceived over-diagnosis of cancer. Furthermore, and most importantly, it provides patients with low-risk disease the lowest possible grade. Indeed, one is the new six.

Competing interests: Dr. Evans has been a consultant on clinical trial design for GE/Omnyx. The remaining authors report no competing personal or financial interests.

This paper has been peer-reviewed. 


\section{References}

1. Gleason DF. Classification of prostatic carcinomas. Cancer Chemother Rep 1966;50:125-28.

2. Eble JN, Sauter G, Epstein JI, Sesterhenn I (Eds): WHO Classification: Pathology and Genetics of Tumours of the Urinary System and Male Genital Organs, 3rd ed. Lyon: IARC Press, 2004.

3. Sobin L, Gospodarowicz M, Wittekind C. TNM classification of malignant tumours. In: UICC, 7th ed. Wiley-Liss, 2009.

4. Epstein Jl, Allsbrook WC Jr, Amin MN, et al. ISUP Grading Committee. The 2005 International Society of Urological Pathology (ISUP) consensus conference on Gleason grading of prostatic carcinoma. Am I Surg Pathol 2005;29:1228-42. http://dx.doi.org/10.1097/01.pas.0000173646.99337.bl

5. Helpap B, Egevad L. The significance of modified Gleason grading of prostatic carcinoma in biopsy and radical prostatectomy specimens. Virchows Arch 2006;449:622-7. http://dx.doi.org/10.1007/ s00428-006-0310-6

6. Billis A, Guimaraes MS, Freitas LL, et al. The impact of the 2005 International Society of Urological Pathology consensus conference on standard Gleason grading of prostatic carcinoma in needle biopsies. J Urol 2008;180:548-52. http://dx.doi.org/10.1016/i.juro.2008.04.018

7. Kuroiwa K, Uchino H, Yokomizo A, et al. Impact of reporting rules of biopsy Gleason score for prostate cancer. J Clin Pathol 2009;62:260-3. http://dx.doi.org/10.1136/icp.2008.060632

8. Resnick MJ, Koyama T, Fan KH, et al. Long-term functional outcomes after treatment for localized prostate cancer. N Engl J Med 2013;368:436-45. http://dx.doi.org/10.1056/NEJMoal209978

9. Esserman $\mathrm{U}$, Thompson IM, Reid B, et al. Addressing over-diagnosis and overtreatment in cancer: A prescription for change. Lancet Oncol 2014;15:e234-42. http://dx.doi.org/10.1016/S14702045(13)70598-9

10. Epstein JI, Egevad L, Amin MB, et al. The 2014 International Society of Urological Pathology (ISUP) consensus conference on Gleason grading of prostatic carcinoma: Definition of grading patterns and proposal for a new grading system. Am I Surg Pathol 2016;40:244-52.

11. Eifler JB, Feng Z, Lin BM, et al. An updated prostate cancer staging nomogram (Partin tables) based on cases from 2006 to 2011. BJU Int 2012;111: 22-9. http://dx.doi.org/10.1111/i.1464410X.2012.11324.x

12. Gleason DF and The Veterans Administration Cooperative Urological Research Group. Histologic grading and clinical staging of prostate carcinoma. In: Tannenbaum M (Ed). Urologic Pathology. Philadelphia: Lea and Febiger, 1977.

13. Pilepich MV, Krall IM, Sause WT, et al. Prognostic factors in carcinoma of the prostate: Analysis of RTOG 75-06. Int J Radiat Oncol Biol Phys 1987;13:339-49. http://dx.doi.org/10.1016/03603016(87)90007-1

14. Bagshaw MA, Cox RS, Ramback JE. Radiation therapy for localized prostate cancer: Justification by long-term followup. Urol Clin Nth Am 1990;17:787-802.

15. Russell KJ, Dunatov C, Hafermann MD, et al. Prostate-specific antigen in the management of patients with localized adenocarcinoma of the prostate treated with primary radiation therapy. J Urol 1991;146:104652.

16. Epstein Jl, Carmichael M, Partin AW, et al. Is tumour volume an independent predictor of progression following radical prostatectomy? A multivariate analysis of 185 clinical stage B adenocarcinomas of the prostate with five years of followup. J Urol 1993;149:1478-81.

17. Ohori M, Goad JR, Wheeler TM, et al. Can radical prostatectomy alter the progression of poorly differentiated prostate cancer? J Urol 1994;152:1843-49

18. Zagers $G K$, Ayala $A G$, von Eschenbach $A C$, et al. The prognostic importance of Gleason grade in prostatic adenocarcinoma: A long-term followup study of 648 patients treated with radiation therapy. Int J Radiat Oncol Biol Phys 1995;31:237-45. http://dx.doi.org/10.1016/0360-3016(94)00323-D

19. Partin AW, Kattan MW, Subomg ENP, et al. Combination of prostate-specific antigen, clinical stage, and Gleason score to predict pathological stage of localized prostate cancer: A multi-institutional update. JAMA 1997;277:1445-51. http://dx.doi.org/10.1001/jama.1997.03540420041027
20. D'Amico AV, Whittington R, Malkowicz SB, et al. The combination of preoperative prostate-specific antigen and preoperative pathological findings to predict prostate-specific antigen outcome in clinically localized prostate cancer. J Urol 1998;160:2096-101. http://dx.doi.org/10.1016/S0022-5347(01)62251-1

21. Freedland SJ, Sutter ME, Naitoh J, et al. Clinical characteristics in Black and White men with prostate cancer in an equal access medical centre. Urology 2000;55:387-90. http://dx.doi.org/10.1016/ S0090-4295(99)00461-6

22. Donohue JF, Bianco FJ Jr, Kuroiwa K et al. Poorly differentiated prostate cancer treated with radical prostatectomy: Long-term outcome and incidence of pathological downgrading. J Urol 2006;176:991-5. http://dx.doi.org/10.1016/i.juro.2006.04.048

23. Makarov DV, Trock BJ, Humphreys EB, et al. Updated nomogram to predict pathologic stage of prostate cancer given prostate-specific antigen level, clinical stage, and biopsy Gleason score (Partin tables) based on cases from 2000 to 2005. Urology 2007;69:1095-101. http://dx.doi.org/10.1016/j. urology.2007.03.042

24. Tolonen TT, Kujala PM, Tammela $L$, et al. Overall and worst Gleason scores are equally good predictors of prostate cancer progression. BMC Urology 2011;11:21. http://dx.doi.org/10.1186/1471-2490-11-21

25. Egevad L, Delahunt B, Evans AJ, et al. International Society of Urological Pathology (ISUP) grading of prostate cancer. Am J Surg Pathol 2016;40:858-61.http://dx.doi.org/10.1097/PAS.0000000000000642

26. Makarov DV, Sanderson H, Partin AW, et al. Gleason score 7 prostate cancer on needle biopsy: Is the prognostic difference in Gleason scores $4+3$ and $3+4$ independent of the number of involved cores? J Urol 2002;167:2440-2. http://dx.doi.org/10.1016/S0022-5347(05)65000-8

27. Wright JL, Salinas CA, Lin DW, et al. Prostate cancer specific mortality and Gleason 7 disease differences in prostate cancer outcomes between cases with Gleason $4+3$ and Gleason $3+4$ tumours in a population-based cohort. J Urol 2009;182:2702-7. http://dx.doi.org/10.1016/i.juro.2009.08.026

28. Zumsteg ZS, Spratt DE, Pei I, et al. A new risk classification system for therapeutic decision-making with intermediate-risk prostate cancer patients undergoing dose-escalated external beam radiation therapy. Eur Urol 2013;64:895-902. http://dx.doi.org/10.1016/i.eururo.2013.03.033

29. Morash C, Tey R, Agbassi C, et al. Active surveillance for the management of localized prostate cancer: Guideline recommendations. Can Urol Assoc J 2015;9:171-8. http://dx.doi.org/10.5489/cuaj.2806

30. Chen RC, Rumble RB, Loblaw DA, et al. Active surveillance for the management of localized prostate cancer (Cancer Care Ontario Guideline): American Society of Clinical Oncology clinical practice guideline endorsement. J Clin Oncol 2016;34:1-10. http://dx.doi.org/10.1200/JC0.2015.65.7759

31. Moch H, Humphrey PA, Ulbright TM, Reuter RE (Eds.). WHO Classification of Tumours of the Urinary System and Male Genital Organs, 4th ed. [Lyon]: IARC Press, 2016.

32. Samaratunga $H$, Delahunt $B$, Gianduzzo $T$, et al. The prognostic significance of the 2014 International Society of Urological Pathology (ISUP) grading system for prostate cancer. Pathology 2015;47:515-9. http://dx.doi.org/10.1097/PAT.0000000000000315

33. Delahunt B, Egevad L, Srigley JR, et al. Validation of International Society of Urological Pathology (ISUP) grading for prostatic adenocarcinoma in thin core biopsies using TROG 03.04 RADAR trial clinical data. Pathology 2015;47:520-5. http://dx.doi.org/10.1097/PAT.0000000000000318

34. Epstein Jl, Zelefsky MJ, Sjoberg DD, et al. A contemporary prostate cancer grading system: A validated alternative to the Gleason score. Eur Urol 2016;69:428-35. http://dx.doi.org/10.1016/i. eururo.2015.06.046

35. Mahal BA, Muralidhar V, Chen YW, et al. Gleason score $5+3=8$ prostate cancer: Much more like Gleason score 9? BJU Int 2016;118:95-101. http://dx.doi.org/10.1111/bju.13239

Correspondence: Dr. John R. Srigley, Trillium Health Partners and University of Toronto, Mississauga, ON, Canada; john.srigley@trilliumhealthpartners.ca 